\title{
Microcytosis: Etiological Discussion about 280 Cases
}

\author{
Khayati S*, Bahri R, El Farssani F, Yahyaoui H, Ait Ameur M, Chakour M
}

Hematology Laboratory, Avicenna Military Hospital in Marrakech, Morocco

Introduction: Anemia is defined by: a decrease in hemoglobin $(\mathrm{Hb})$ level based on normal values for age. We talk about microcytosis for an average globular volume (MCV); whose reference value is between 80 and $100 \mathrm{fl}$ in adults; less than $80 \mathrm{fl}$. Material and method: We conducted a prospective study over a period of two months in the hematology laboratory of the Avicenne hospital in Marrakech. Complete blood counts (CBCs) were performed on samples. A blood smear, stained with the May-Gründwald-Giemsa stain, was performed for all patients. Were included in our study, all CBCs including MCV $<80 \mathrm{fL}$ in adults and $<71 \mathrm{fL}$ in children. Results: During the study period, 3682 NFS were performed. 280 microcytoses were detected. The average VGM was $73.8 \mathrm{fl}$. In the blood smear, the most common blood cell abnormalities were anisopoikilocytosis (97\%), microcytosis (90\%) and hypochromia (85\%). Exploration of these microcytoses revealed a predominance of iron deficiency, found in $48 \%$ of cases, $21 \%$ of pseudopolyglobulie, $18 \%$ of inflammation, $3 \%$ of hemoglobinopathy, and in $10 \%$ of cases, no etiology was found. Conclusion: This study confirmed the value of a complementary assessment when detecting microcytosis. In particular, it can detect iron deficiencies and hemoglobin abnormalities. In the event of a difficult etiological diagnosis, cooperation between clinician and biologist is essential.

Keywords: Hematology, anemia, microcytosis, CBC, blood smear.

Copyright $(92020$ The Author(s): This is an open-access article distributed under the terms of the Creative Commons Attribution 4.0 International License (CC BY-NC 4.0) which permits unrestricted use, distribution, and reproduction in any medium for non-commercial use provided the original author and source are credited.

\section{INTRODUCTION}

Anemia is defined by: a decrease in hemoglobin $(\mathrm{Hb})$ level based on normal values for age $(<13 \mathrm{~g} / \mathrm{dL}$ in men, $<12 \mathrm{~g} / \mathrm{dL}$ in women, $<11 \mathrm{~g} / \mathrm{dL}$ in children, and $<10.5 \mathrm{~g} / \mathrm{dL}$ in pregnant women). We talk about microcytosis for an average globular volume (MCV); whose reference value is between 80 and $100 \mathrm{fl}$ in adults; less than $80 \mathrm{fl}$. The causes of microcytic anemia are mainly iron deficiency, chronic inflammatory conditions and hemoglobinopathies. The objective of our work is to determine the frequency of microcytic anemia, as well as to explain microcytosis found during a biological assessment.

\section{MATERIAL AND METHOD}

We conducted a prospective study over a period of two months in the hematology laboratory of the Avicenne hospital in Marrakech. Complete blood counts (CBCs) were performed on samples taken from the various hospital departments and from the laboratory collection room (for non-hospitalized patients). A blood smear, stained with the May-
Gründwald-Giemsa stain, was performed for all patients. Were included in our study, all CBCs including MCV $<80 \mathrm{fL}$ in adults and $<71 \mathrm{fL}$ in children. Any sample not respecting the pre-analytical phase was excluded.

\section{RESULT}

During the study period, 3682 NFS were performed. 280 microcytoses were detected $(7 \%$ of the population studied). $53 \%$ of these microcytoses were found in male patients. The mean age of all patients was 41 years.

The average VGM was $73.8 \mathrm{fl}$ with extremes ranging from $55.1 \mathrm{fl}$ to $79.9 \mathrm{fl}$. In the blood smear, the most common blood cell abnormalities were anisopoikilocytosis (97\%), microcytosis (90\%) and hypochromia $(85 \%)$. Other abnormalities were also found in lower percentages: target red blood cells $(26 \%)$, dacryocytes $(19 \%)$ as well as one case of an eliptocyte (Figure-1). 


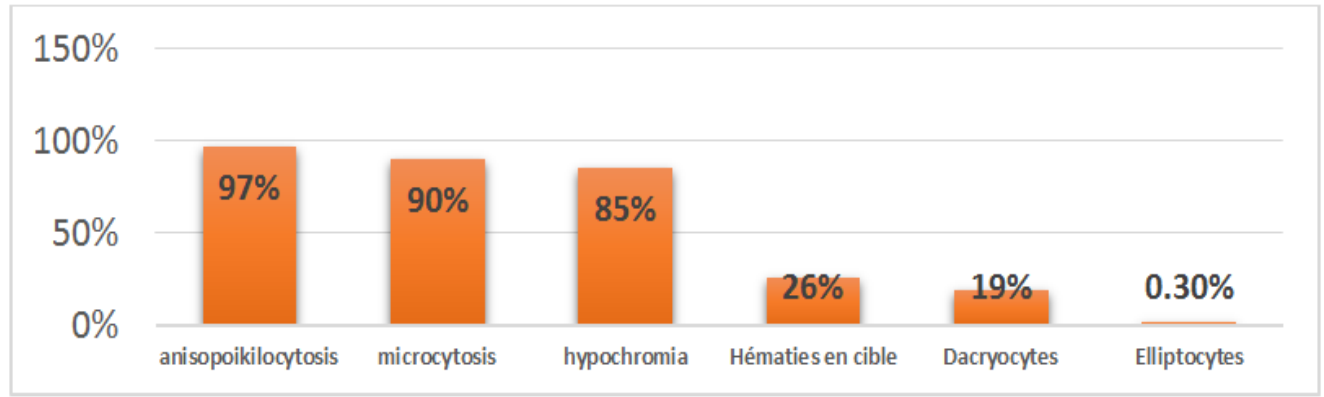

Fig-1: Red blood cell abnormalities in blood smears

Exploration of these microcytoses revealed a predominance of iron deficiency, found in $48 \%$ of cases. It affected the female population in $59 \%$ of cases. In the majority of cases (70\%), microcytosis was associated with anemia. The VGM was between $65 \mathrm{fl}$ and $80 \mathrm{fl}$.

In $18 \%$ of cases, inflammation, revealed by the increase in CRP, was found.

Hemoglobin electrophoresis was not requested for all of our patients. Only 3\% were known to have hemoglobinopathy. However, we found $21 \%$ of pseudopolyglobulie on the performed CBCs, the MCV of which was between $60 \mathrm{fl}$ and $80 \mathrm{fl}$.

Hemoglobinopathy cases were mainly represented by $\beta$-thalassemia minor found in 6 patients, as well as by sickle cell disease in its heterozygous form, found in 2 patients. The MCV for hemoglobinopathies was between $60 \mathrm{fl}$ and $70 \mathrm{fl}$.

In $10 \%$ of cases, the workup did not reveal any abnormalities except microcytosis, apart from electrophoresis of hemoglobin which was not done (Figure-2).

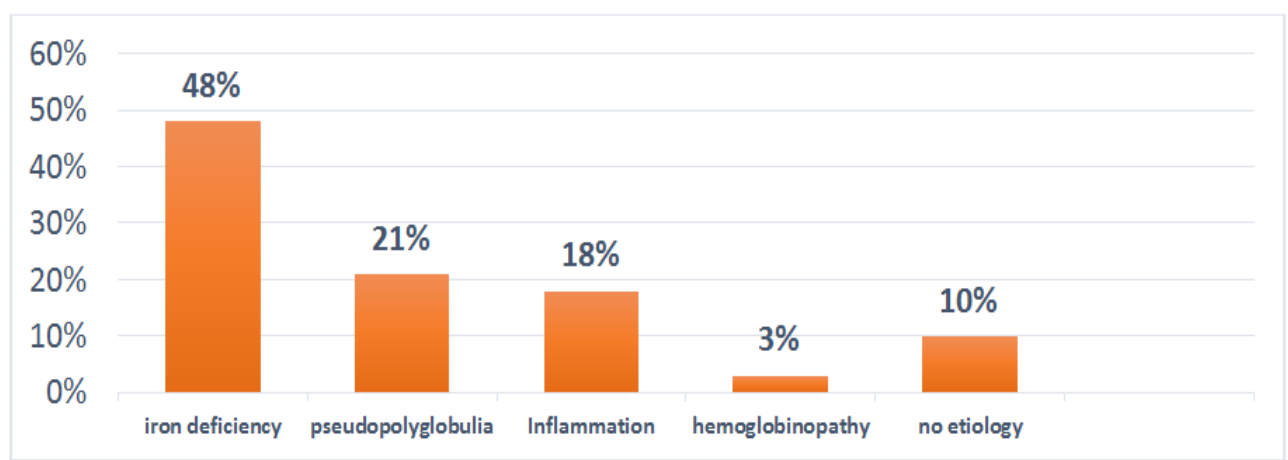

Fig-2: Percentage of etiologies of microcytosis in the study population

\section{DISCUSSION}

Iron deficiency is the most common etiology of microcytosis. Lack of intake or gastrointestinal bleeding may be mentioned. In young women, menstrual losses lead to this situation $[1,2]$.

Faced with an iron deficiency, the etiological assessment looking for a deficiency of intake or occult bleeding is negative in about $30 \%$ of cases. Several studies have shown that these unexplained deficiencies may be due to poor absorption associated with autoimmune gastritis with or without Helicobacter pylori infection. Celiac disease should also be looked for, but found less frequently [3-6]. Microcytosis is not an early marker of deficiency, which is first evidenced by a decrease in ferritin and then in the saturation coefficient of transferrin [7].

In the study carried out in France by Désidéri et al., [7], iron deficiency was found in $44 \%$ of cases, the etiology predominant in the series. This rate is close to that of our study (48\%).

Hemoglobin electrophoresis can detect the main variants of hemoglobin that are accompanied by microcytosis $(\mathrm{C}, \mathrm{E})$ but also other variants, especially if $\alpha$-thalassemia is associated. HB S is only accompanied by microcytosis in association with $\alpha$-thalassemia [7].

As regards the hemoglobinopathies found in the Désideri study [7] (26\%), their rates are much higher than ours (3\%). This is due to the fact that all their patients underwent hemoglobin electrophoresis while we only took into account the hemoglobinopathies already documented. Heterozygous $\beta$-thalassemias were the majority in our series. It is the same for the French series [7]. In the latter, MCV was less than $70 \mathrm{fl}$ in $66 \%$ of heterozygous $\beta$-thalassemias. While in our study, the MCV for hemoglobinopathies was between $60 \mathrm{fl}$ and $70 \mathrm{fl}$. In another study conducted 
in Iraq, in patients with sickle cell traits, MCV ranged from $45 \mathrm{fL}$ to $94 \mathrm{fl}$ with microcytosis reported in $85.26 \%$ of cases [8]. In the population of this study, only heterozygous forms of $\beta$-thalassemia were found. They are mostly asymptomatic.

For pseudopolyglobulias, they were found, in the study by Désidéri [7], in $22.9 \%$ of cases, without any other anomaly being able to be demonstrated. Some of his patients presented with sometimes very severe microcytosis which could suggest $\alpha$-thalassemia minor. In our study, cases of pseudopolycythemia represented $21 \%$, a rate similar to the French study. However, hemoglobin electrophoresis should be performed in our patients for hemoglobinopathy.

The association of microcytosis and polycythemia without other abnormality suggests $\alpha$ thalassemia minor. Thalassemia minor is characterized by the total or partial deletion of one or two genes encoding the $\alpha$ subunits of globin. It is manifested by microcytic pseudopolycythemia and normal levels of $\mathrm{F}$ and A2 hemoglobin. The positive diagnosis is made by molecular biology [7].

With regard to inflammation situations, we note a greater number of cases $(18 \%)$ compared to the Désideri series (9.3\%) [7]. The same is true for cases without obvious anomaly, found in $10 \%$ in our series and $5.6 \%$ in the French study [7]. However, the latter rate is likely to increase after completing patient workup with hemoglobin electrophoresis.

\section{CONCLUSION}

This study confirmed the value of a complementary assessment when detecting microcytosis. In particular, it can detect iron deficiencies and hemoglobin abnormalities. Due to the contributions of molecular genetics, less frequent pathologies can be easily researched. In the event of a difficult etiological diagnosis, cooperation between clinician and biologist is essential, making it possible to propose the most relevant explorations on a case-bycase basis.

\section{REFERENCES}

1. Espanel C, Kafando E, Hérault B, Petit A, Hérault $\mathrm{O}$, Binet C. Anémies ferriprives: signes d'appel, diagnostic et prise en charge. Transf Clin Biol. 2007; 14:21-7.

2. Hercberg S. La carence martiale en France: prévalence et prévention. Bull Acad Natl Med. 2005;1879(8):1623-30.

3. Rousselot P. Que faire devant une carence martiale inexpliquée. Hématologie. 2006;4:220.

4. Hershko C, Hoffbrand AV, Keret D, Souroujon M, Maschler I, Monselise Y. Role of autoimmune gastritis, Helicobacter pylori and coeliac disease inrefractory inrefractory or unexplained iron deficiency anemia. Haematologica. 2005; 90:58595.

5. Hershko C, Ronson A, Souroujon M, Maschler I, Heyd J, Patz J. Variable hemato-logic presentation of autoimmune gastritis: age-related progression from irondeficiency to cobalamin depletion. Blood. 2006;107:1673-9.

6. Zulphiqar AA, Dramé M, Pennaforte JL, Novella JL, Vogel T, Andres A. Carence martiale et maladie de Biermer: une association rare ? Ann Biol Clin. 2015;73:420-6.

7. Désidéri-Vaillant C, Rouby Y, Guedes J, Kerdonkuf C, Valero E, Drouillard I, Corbé H, Le Guen P. Signification biologique de 410 microcytoses de découverte fortuite chez des adultes jeunes. Pathologie Biologie. 2009 Sep 1;57(6):496-9.

8. Jaber RZ, Hassan MK, Al-Salait SK. Microcytosis in children and adolescents with the sickle cell trait in Basra, Iraq. Blood research. 2019 Mar $1 ; 54(1): 38-44$. 